\title{
EBOOKS FROM YOUR LIBRARY SERVICE
}

Your BDA Library service is available at the touch of a button - you don't need to visit us to make use of our resources, which include downloadable revision bundles, document supply service, evidence-based literature searches, and over 540 eBooks.

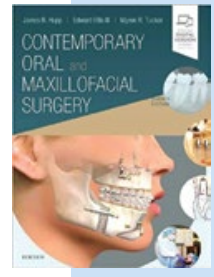

CONTEMPORARY ORAL AND MAXILLOFACIAL SURGERY, 7TH EDITION James Hupp, Myron Tucker, Edward Ellis 2018; Mosby 721 pages eISBN 9780323552226

Now in its seventh edition, Contemporary Oral and Maxillofacial Surgery provides both dental students and practising dentists the fundamental principles of clinical evaluation, treatment planning, and surgical care for patients with diseases and deformities of the oral and maxillofacial region.

This book provides basic theoretical background information to assist in the development of your skills in evaluation, diagnosis, and patient management. The authors present a comprehensive description of basic oral surgery procedures, and provide information on advanced, more complex surgical evaluation and management of patients with problems that are typically managed by oral and maxillofacial surgeons but are commonly first seen and evaluated by other dental practitioners. Enriched with colour photographs and drawings, surgical techniques are made readily understandable, along with a detailed patient evaluation section that includes guidelines on when to refer patients to specialists and how to provide supportive postoperative care.

\section{INGLE'S ENDODONTICS, 7TH EDITION}

= Ilan Rotstein, John I. Ingle

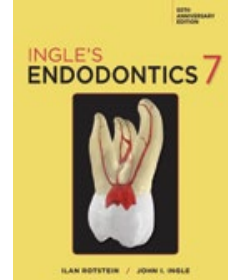

2019; People's Medical

Publishing House

1246 pages

eISBN 9781607959359

Ingle's Endodontics, $7^{\text {th }}$ edition, is the most recent revision of the text that has been known as the 'Bible of Endodontics' for half a century. A whopping 86 authors contributed cuttingedge knowledge and updates on topics that have formed the core of this book for years and new chapters reflect the ways in which the field of endodontics has evolved.
In this $50^{\text {th }}$ anniversary landmark edition, the text continues to serve as the reference standard for the basic and advanced tenets of endodontology education at both the undergraduate and post-graduate levels. It continues the tradition of including an international group of authors, and is divided into three main sections: The Science of Endodontics, The Practice of Endodontics, and Interdisciplinary Endodontics. Designed to be easy to read, the 40 chapters are focused and bite-sized, enhanced with colour illustrations and summary tables and extensively referenced to aid the reader with the appropriate evidence base.

\section{ESSENTIALS OF DENTAL RADIOGRAPHY AND RADIOLOGY, 6TH EDITION}

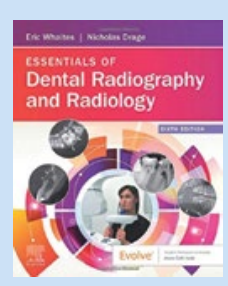

Eric Whaites, Nicholas

Drage 2020; Elsevier 528 pages eISBN 9780702076893 A concise and updated presentation of modern dental radiography and

radiology, providing a basic, but comprehensive, practical account of the essential subject matter of both dental radiography and radiology as required by undergraduate and postgraduate dental students.

This is an updated and refreshed edition of this established textbook. For the first time, there are colour images throughout, and nearly every chapter has been revised. The authors have aligned the content and terminology closely with the new international classifications in relation to cysts, tumours, bone lesions and diseases, caries and periodontal diseases. Many new radiographs have been added and emphasis has been placed on examples showing normal radiographic anatomy, on the principle that the main reason for radiographic imaging is to be able to distinguish the difference in appearance between normal and abnormal. The book is primarily a digestible manual rather than a comprehensive reference, but the content remains sufficiently broad, detailed and up-to-date to satisfy the requirements of most undergraduate and postgraduate students.

\section{ODELL'S CLINICAL PROBLEM SOLVING IN DENTISTRY, 4TH EDITION}

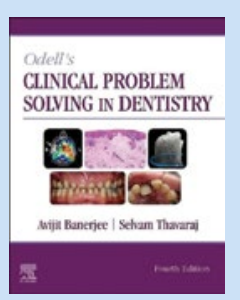

Avijit Banerjee, Selvam Thavaraj 2020; Elsevier 464 pages eISBN 9780702077012 A step-by-step guide to practical care planning and management of

a wide variety of clinical case scenarios encountered in the primary and secondary dental care setting. Covering all the core aspects of oral health care delivery, this resource is useful to all general dental practitioners and dental therapists, both qualified and in training, undergraduates or postgraduates alike.

Designed to help you use the knowledge gained in a clinically useful and practical way, this highly visual guide has over 350 colour illustrations, artwork and tables presenting clinical, diagnostic and practical information in an easy-to-follow structure. Integrating material from all the dental disciplines in order to cover an extensive range of clinical problems, cases have been updated with appropriate changes in national guidance, relevant legislation and advances in management practices. This new edition of a popular text provides you with a wide mix of scenarios within the scope of practice of a modern general oral healthcare practitioner and their team, including patient behaviour management issues, the use of digital dentistry, management and maintenance of dental implant cases and domiciliary care provision.

\section{Further information}

Go to www.bda.org/library/student-services to view our range of student services.

Any questions or comments?

Email library@bda.org or call 02075634545.

https://doi.org/10.1038/s41406-020-0170-6 